Rev. Hist., N²8, vol. 1, Enero-Junio 2021: 541-565

ISSN 0717-8832

https://doi.org/10.29393/RH28-20CCCA20020

\title{
Conductismo y cambio social: Programa de Economía de Fichas en el Hospital Psiquiátrico El Peral. Chile, 1976-1978*
}

\author{
Behaviorism and social change: Token Economy Program at El Peral Psychiatric \\ Hospital. Chile, 1976-1978
}

\author{
Claudia Araya Ibacache** \\ César Leyton Robinson ${ }^{* * *}$
}

\section{RESUMEN}

En Santiago de Chile, entre los años de 1976 y 1978 se llevó a cabo en el Hospital Psiquiátrico El Peral un programa de rehabilitación para pacientes psiquiátricos institucionalizados, basado en los principios del análisis y modificación del comportamiento, conocido como "Terapia de Economía de Fichas". El Programa se aplicó en un contexto de completo abandono de los pacientes del hospital y de violaciones de derechos humanos fundamentales en todo el país por parte de la Dictadura Militar chilena. Planteamos que la "Terapia de Economía de Fichas" fue un intento tanto de restituir la dignidad a los pacientes, como de darle continuidad a los programas de salud mental comunitaria que se habían implementado en Santiago en el período inmediatamente anterior al Golpe de Estado de 1973 y que fueron violentamente interrumpidos por el gobierno de Augusto Pinochet.

Palabras clave: Conductismo en Chile, Dictadura Militar, Luis Montesinos, Psiquiatría Intracomunitaria, Psicología Pública, Salud Mental.

\section{ABSTRACT}

In Santiago de Chile, between 1976 and 1978, a rehabilitation program for institutionalized psychiatric patients was carried out at the El Peral Psychiatric Hospital, based on the principles of behavior analysis and modification, known as "Token Economy Therapy". The Program was applied in a context of complete abandonment of Hospital patients and violations of fundamental human rights throughout the country by the Chilean Military Dictatorship. We propose that the "Token Economy Therapy" was an attempt both to restore dignity to patients, and to give continuity to the community mental health

\footnotetext{
* Esta investigación forma parte del Proyecto Fondecyt Posdoctorado N³180429, "Antecedentes, propuestas y formulación de políticas de salud mental en Chile, 1940-1990".

** Doctora en Historia, Universidad Católica de Chile, Investigadora Programa de Estudios Médicos Humanísticos de la Universidad Católica de Chile, Facultad de Medicina, Universidad Católica de Chile, Chile. ORCID: https://orcid.org/0000-0001-7353-0123.Correo electrónico: c.arayaibacache@gmail.com.

*** Doctor en Historia, Universidad de Chile, Museo Nacional de Odontología, Facultad de Odontología, Universidad de Chile, Chile. https://orcid.org/0000-0002-2825-6097. Correo electrónico: cesarleytonrobinson70@gmail.com
} 
programs that had been implemented in Santiago in the period immediately prior to the 1973 coup. and that they were violently interrupted by the government of Augusto Pinochet.

Keywords: Behaviorism in Chile, Military Dictatorship, Luis Montesinos, Intracommunity Psychiatry, Public Psychology, Mental Health

Recibido: octubre 2020

Aceptado: abril 2021

"Siempre me llamó poderosamente la atención la presencia de estos hombres en las faldas de los cerros, vistiendo uniforme militar. Por ello desde las colinas, algunos retozando al sol, otros en su mundo interior y todos con la mirada perdida, parecían una milicia derrotada arrastrando sus miserias a casa, después de penosas batallas" ${ }^{1}$.

“La psicoterapia en sí misma no es una técnica de dominio. Pienso que el tratamiento psicoterapéutico es como la relación médico-paciente, que puede ser de dominio o de libertad. [...] si la relación no es de reciprocidad y hay solo dependencia, esta psicoterapia o esta relación será solamente de dominio, y esto desnaturalizará la lógica de la psicoterapia que es un medio para ayudar a las personas que sufren" ${ }^{2}$.

\section{Introducción}

En Santiago de Chile, entre 1976 y 1978, se implementó en el Hospital Psiquiátrico El Peral ${ }^{3}$, un programa de rehabilitación para pacientes crónicos, basado en los principios del análisis y modificación del comportamiento, conocido como Terapia de Economía de Fichas. El Programa se aplicó en un contexto de abandono de los pacientes del Hospital Psiquiátrico El Peral y de violaciones a los derechos humanos por parte de la dictadura militar chilena. La terapia en cuestión tuvo sus raíces en dos momentos de transformación de la psiquiatría y de la psicología en Chile. Nos referimos a la psiquiatría intracomunitaria y a la terapia conductista respectivamente. La hipótesis es que por medio de esta conjunción se buscaba instalar un programa que permitiera mantener políticas que, a pesar de que habían sido evaluadas como exitosas, fueron interrumpidas violentamente. Por su parte, a través de la terapia, se esperaba enfrentar la elevada cronicidad de los pacientes internados.

\footnotetext{
1 Montesinos, Luis. 2018. "Intervención cultural en pacientes psiquiátricos crónicos del Hospital Sanatorio El Peral: 40 años después”, en Revista de Psicología, № 27, Vol 1, Santiago, pp.1-6.

2 Basaglia, Franco. 2013. La condena de ser loco y pobre. Alternativas al manicomio, Buenos Aires, Topía, p.74.

${ }^{3}$ A lo largo de su historia, el Hospital Psiquiátrico El Peral ha tenido distintos nombres. Para evitar confusiones usaremos sólo el actual.
} 
La historia asilar chilena comienza en 1852 con la fundación de la primera Casa de Orates de Santiago. Desde ese momento, y hasta la reforma psiquiátrica iniciada en la década de 1990, la asistencia mental mantuvo un marcado carácter asilar ${ }^{4}$. No obstante que, desde la segunda mitad del siglo pasado, el país había comenzado a desarrollar investigación epidemiológica que había derivado en los primeros planes nacionales de control del alcoholismo y en la incorporación de conceptos propios de la salud mental como "política de sector", "programa integral" y "unidad de salud mental"5. Hacia fines de la década de 1960, el psiquiatra Juan Marconi y su equipo, implementaron los primeros programas de salud mental intracomunitaria en Santiago. Aun cuando se aplicaron en un área limitada de la capital del país, fueron producto de un proceso de cambio social, cultural y académico que venía gestándose desde mediados de siglo. Cuando los programas se encontraban en plena vigencia fueron desmantelados luego del Golpe Militar, lo que contribuyó, entre otros factores, a extender el sistema asilar hasta fines del siglo veinte. Por su parte, el conductismo se instaló en las universidades chilenas a fines de la década de 1960 como un pensamiento crítico hacia tendencias filosóficas animistas y fenomenológicas de retórica objetivadora, que dejaban de lado la ideología y los contextos sociales, factores históricos fundamentales en los años sesenta. Luego del Golpe Militar, las universidades fueron intervenidas y los profesores conductistas exonerados y perseguidos.

En este contexto político se instaló, en 1976, en el Hospital Psiquiátrico El Peral, una terapia de rehabilitación de base conductista para pacientes crónicos. Entre los objetivos propuestos para esta investigación están conocer los alcances de esta experiencia terapéutica, su vinculación con las políticas públicas de salud mental que se habían desarrollado en el país a partir de la década de 1950, interrumpidas en 1973, y finalmente, identificar los propósitos que el equipo que implementó esta terapia definió para su desarrollo y proyección como política pública a aplicar en otros hospitales de enfermos mentales crónicos. En el primer apartado abordaremos brevemente la situación del Hospital El Peral, principalmente en la década de 1970. La historiografía chilena sobre instituciones sanitarias en general y asilos y hospitales psiquiátricos en particular ha sido escasa. La falta de archivos y de políticas de resguardo de documentos ha dificultado su desarrollo. Por esta razón incluimos una breve reseña sobre la Historia del Hospital Psiquiátrico El Peral que permita dar cuenta de la situación de abandono de los pacientes, así como de la ausencia de programas terapéuticos para enfermos crónicos en la década de 1970.

\footnotetext{
${ }^{4}$ Marconi, Juan. 1998. Del asilo a la comunidad: 50 años de psiquiatría chilena, 1948-1998. Un testimonio personal, Santiago, documento inédito.

${ }^{5}$ Araya, Claudia; Martínez, Camila. 2020. "Epidemiología de los trastornos mentales en Chile y su impacto en las políticas públicas de salud mental, 1950-1973", en Asclepio, № 1, Vol. 73, Santiago, p. 349. Doi: https://doi.org/10.3989/asclepio.2021.15.
} 
En la segunda parte nos referiremos al origen del conductismo y a su vinculación con los procesos de reforma universitaria y cambio social que venía experimentando el país desde mediados de la década de 1960. La Terapia de Economía de Fichas (TEF) que se aplicó en el Hospital Psiquiátrico El Peral fue un programa de rehabilitación basado en el conductismo; sin embargo, a diferencia de otras terapias psicológicas conductistas que se aplicaban en Chile, la TEF tomó aspectos de los programas de psiquiatría comunitaria implementados en el área sur de Santiago de Chile, entre 1968 y 1973, lo que la transforma en una terapia inédita en la historia de la rehabilitación de los pacientes mentales en Chile. Finalmente, con esos antecedentes, abordaremos la gestión, implementación y evolución del Programa de Economía de Fichas en el Hospital Psiquiátrico El Peral.

\section{El Hospital Psiquiátrico El Peral}

La asistencia pública de los enfermos psiquiátricos crónicos en el mundo occidental ha sido uno de los temas probablemente más debatidos por la historiografía y, al mismo tiempo, uno de los más ignorados desde el punto de vista sanitario. Aun cuando desde mediados del siglo XIX europeo, la llamada psiquiatría asilar venía siendo cuestionada, no fue hasta terminada la Segunda Guerra Mundial que cayó en su mayor punto de desprestigio. En Chile, a partir de 1920, se introducen una serie de cambios dirigidos a modernizar la principal institución asilar del país, el Manicomio Nacional. En este contexto, se funda, en 1928, el Hospital Psiquiátrico El Peral, en el área sur oriente de Santiago. Hacia fines de la década de 1970, el país contaba con tres hospitales psiquiátricos, dos en la capital -El Peral y el actual Instituto Psiquiátrico Dr. José Horwitz Barak-; y el Hospital Dr. Philippe Pinel, en Putaendo, ciudad cercana a Santiago. Así, al histórico carácter asilar de la asistencia psiquiátrica chilena, se sumaba un marcado centralismo.

El Hospital Psiquiátrico El Peral, fundado como hospital opendoor, formaba parte de un proyecto ambicioso de transformación de la asistencia asilar, que prometía poner al país, "a la vanguardia en el continente americano" ${ }^{6}$. Sin embargo, esta promesa de modernidad sucumbió rápidamente ante la enorme presencia del custodialismo en la institucionalidad psiquiátrica chilena. Diversos autores coinciden en que "hacia la década del 60 y 70 se había transformado en un depósito de personas afectadas por una variedad de patologías psiquiátricas... y carencias sociales"7 . Entre 1969 y 1972, bajo la dirección de la psiquiatra Mary Hamuy, se preparó a un grupo de 30 internos para egresar y trasladarse a departamentos en Quebrada Verde, pagados

\footnotetext{
6 "El Open Door de El Peral será dentro de poco un motivo de orgullo para el país", Diario La Nación, 25 de marzo de 1929, p.1.

7 Gómez, Mauricio. 2005. "La reconversión del Hospital Psiquiátrico El Peral en Red Comunitaria de Salud Mental y Psiquiatría”, en Cuadernos Médico Sociales, N45, pp.285-299, Santiago, p.286.
} 
por el Hospital, donde vivirían en comunidad ${ }^{8}$. Los intentos de cambio iniciados por Hamuy fueron muy resistidos por la comunidad hospitalaria, lo que llevó a abortar la experiencia y cambiar el enfoque por otro de corte tradicional ${ }^{9}$. En 1973, el Hospital fue intervenido y el ejército se hizo cargo de la dirección administrativa hasta $1974^{10}$. En el invierno de ese año de 1974 más de 60 pacientes murieron de frío ${ }^{11}$.

Hacia finales de esa década de 1970, todos los índices analizados del Hospital El Peral evidenciaban que su principal función era la custodia y no la rehabilitación ${ }^{12}$. Uno de esos índices era la escasa participación de los familiares en la organización, alrededor de un 30\%; mientras que una parte aún más pequeña llegaba a comprometerse con el proceso de rehabilitación ${ }^{13}$. Caballero y Liberman, mediante un trabajo de investigación de campo, establecieron para el período 1928-1980 tres etapas en cuanto al desarrollo tecnológico del Hospital. Desde sus orígenes hasta 1974, lo central fue su estructura asilar y una tecnología exclusivamente basada en psicofarmacología y terapia electroconvulsiva, con tasas de alta muy bajas, la mayoría por defunción de los internos. En una segunda etapa, entre 1976 y 1978, se incorporó un grupo de psicólogos, los que instalaron un Programa de Economía de Fichas, inédito hasta ese momento en el trabajo terapéutico del Hospital. Los avances mostrados por el Programa durante estos dos años abrieron la posibilidad de proyectarlo a toda la comunidad hospitalaria. Sin embargo, llegado el momento en el cual se requirió una redefinición estructural para su continuidad, se produjeron conflictos entre la dirección y el equipo terapéutico que llevaron a este último a abandonar la organización. A partir de ese momento, inició de la tercera etapa (1979-1980), en que "los programas de rehabilitación fueron paralizándose en forma progresiva"14.

\section{Psicología conductista en Chile}

Hacia fines de la década de 1960, el auge de las ciencias sociales y la reforma universitaria favorecieron el inicio del proceso de democratización académica y de legitimación científica de la carrera de psicología. La Reforma, iniciada en 1967, propició el surgimiento del

\footnotetext{
8 Becerra, Armando. 2018. Entrevista personal. Becerra, hoy retirado, era auxiliar de enfermería del Hospital Psiquiátrico El Peral y la Dirección le solicitó dirigir el hogar protegido. Sostiene que tras el Golpe Militar se dio la orden de desmantelar los departamentos y acabar con el programa.

9 Gómez, Mauricio; Villanueva, Mario. 2010. "El Hospital Psiquiátrico El Peral”, en Armijo, M. Alejandra ed. La psiquiatría en Chile. Apuntes para una historia, Santiago, Royal Pharma, pp.30-47, p.33.

10 Zanguellini, Germán. 1977. "Antecedentes Históricos". Localizado en Archivo Hospital Psiquiátrico El Peral, Santiago, Serie Documentos Históricos, p.5.

${ }_{11}$ Contreras, Angélica. 2017. Entrevista personal. Contreras, fue funcionaria del Hospital Psiquiátrico El Peral desde 1973 a 2017.

12 Caballero, María Soledad; Liberman, Lucía. 1980. Estudio diagnóstico de dos hospitales psiquiátricos chilenos, Pontificia Universidad Católica de Chile, Tesis para optar al título de psicólogo.

13 Ídem, p.168.

${ }^{14}$ Ibídem, p.199.
} 
Departamento de Psicología en la Universidad de Chile, mientras que la Universidad Católica proporcionó la legitimidad académica y democrática para introducir cambios curriculares, muy resistidos inicialmente por la institución, que buscaban darle a la psicología un carácter científico $^{15}$. Respecto a las terapias conductistas, aun cuando hubo experiencias previas en el país ${ }^{16}$, diversos autores coinciden en que fue Sergio Yulis ${ }^{17}$ su introductor hacia fines de la década de $1960^{18}$. Su auge se dio en Chile entre 1968 y $1973^{19}$

Yulis llegó a la Universidad Católica en 1968 y de inmediato comenzó a hacer clases sobre conductismo ${ }^{20}$. Hasta ese momento la Escuela de Psicología tenía "una fuerte impronta fenomenológica y psicoanalítica" ${ }^{21}$ y "la corriente conductista, era muy poco valorada allí" 22. La psicóloga Miren Busto, estudiante de los primeros cursos de Yulis, recuerda, además de su seriedad y rigurosidad que:

15 Camus, Pablo; Muñoz, Enrique. 2017. Psicología en la UC. Sesenta años de sueños y realizaciones, Santiago, Ediciones Universidad Católica.

${ }^{16}$ Habría sido Juan Marconi el primero en traer desde Inglaterra, a fines de la década de 1960, la obra de Hans Eysenck, Behavior therapy and the neuroses. Leonardo Muñoz y Patricia Hamel iniciaron la terapia conductual en niños enuréticos y luego en pacientes con fobias, disfunciones sexuales y dependencias. En 1975, el mismo Muñoz desarrolló las terapias de descondicionamiento de fobias, biofeedback y economía de fichas. Teresa Pinto-Hamuy, M. de los Ángeles Saavedra y Guy Santibáñez, fueron pioneros en investigación conductual en el Laboratorio de Psicofisiología de la Universidad de Chile. Ver Gómez, Alejandro. 2010. "La terapia cognitivo-conductual”, en Armijo, M. Alejandra ed. La psiquiatría en Chile. Apuntes para una historia, Santiago, Royal Pharma, pp.216-218.

${ }^{17}$ Sergio Yulis nació a mediados de la década de 1930 en Santiago. Estudió psicología en la Universidad de Chile entre 1958 y 1962. En 1968 obtuvo un doctorado en Psicología Clínica en la Universidad de lowa. Fue director del Servicio Psicológico de la Clínica de Salud Mental de Norristown, Pensilvania.

18 Laborda, Mario; Míguez, Gonzalo; Quezada, Vanetza et al. "Notas para una historia", p.48. Para los aportes pioneros de Sergio Yulis, ver también Vera-Villarroel, Pablo; Montesinos, Luis; Prieto, Arturo. 2010. "Historia del análisis y terapia del comportamiento en Chile", en Laborda, Mario; Quezada, Vanetza eds. Notas históricas de la psicología en Chile, Santiago, Universitaria, pp.283-303, p.283. Dorna, Alejandro. 1982. "La psicología del comportamiento en Chile entre los años 1970 y 1973", en Revista Latinoamericana de Psicología, № 14, Vol 2, Bogotá, pp.147-155.

19 Laborda, Mario; Míguez, Gonzalo; Quezada, Vanetza; Lira, Daniela; Arriaza, Tomás. 2019. “Notas para una historia del enfoque conductual en Chile", en Flores, Carlos; Mateos, Laura, coord. Recuento histórico del análisis de la conducta, Guadalajara, Universidad de Guadalajara, pp.39-81.

20 Aunque para muchos sudamericanos el enfoque skinneriano suponía un decisivo avance en el plano de la objetividad científica de la psicología, el predominio de un sentimiento antiestadounidense hizo que muchos vieran en el conductismo un mecanicismo peligroso, ajeno a la complejidad de la naturaleza humana. La idea del control de la conducta iba en contradicción con la forma de pensar de muchos latinoamericanos que terminarían viendo en Skinner un mensajero del imperialismo. León, Ramón. 2014. "Notas acerca de psicólogos y teorías psicológicas de Europa Oriental en la historia de la psicología de América del Sur", en Liberabit, Vol. 20, № 1, Lima, pp.55-72, p.65. En Chile, habría habido una desconfianza creciente sobre las connotaciones ideológicas del conductismo, proveniente de la utilización de la ciencia y la tecnología. Ver Dorna, Alejandro. 1982. "La psicología del comportamiento", p.149.

${ }^{21}$ Quezada, Vanetza; Vergés, Álvaro; Laborda, Mario. 2014. “Sergio Yulis: Pasado y Presente del Enfoque Conductual en Chile", en Psykhe, Vol. 23, №1, pp.1-11, p.2.

22 Luco, Alfonso. 2010. La psicología en Chile. Ciencia, disciplina y profesión, Santiago, Catalonia, p.122. 
"había revuelo entre los profesores por este tipo que venía con una forma de hacer psicología materialista, poco profunda, cosificadora del ser humano [...] la atmósfera académica estaba fuertemente tensionada por abundantes prejuicios hacia el conductismo. Se decía que el conductismo se había originado en la Unión Soviética, que era reduccionista, que no tomaba al ser humano en su totalidad. Lo poco que uno había estudiado en la Escuela era como estudiar al diablo. El conductismo era lo peor..." ${ }^{23}$.

Por otra parte, según Busto, Sergio Yulis "evitaba emitir juicios", salvo sobre el psicoanálisis, "al que odiaba profundamente" ${ }^{24}$. Más allá de estos comentarios, los testimonios recogidos por Pablo Camus y Enrique Muñoz concuerdan en que, hasta la llegada de Yulis, la carrera de psicología de la Universidad Católica era más un colegio particular pagado que una escuela universitaria. En 1970, Yulis es electo director de la Escuela de Psicología. Durante su campaña, instaló en el debate la idea de que el psicólogo debía asumirse como "un agente de cambio", dejando atrás la figura del "psicometrista" que lo caracterizaba hasta ese momento ${ }^{25}$. Esta propuesta se tradujo, según Busto, en "sacar la psicología de la universidad a las poblaciones" 26. Hay coincidencia entre los estudiosos de la obra de Yulis, de que su rigurosidad profesional y su compromiso con los cambios políticos que vivía el país, lo convirtieron en "una figura fundamental en la historia de la psicología en Chile y Latinoamérica" ${ }^{27}$. Aunque no militaba formalmente en ningún partido, tuvo una activa participación en el gobierno de la Unidad Popular, "algo que, era común a la mayoría de los conductistas chilenos de la época" ${ }^{28}$, los que se alinearon principalmente con el gobierno de Salvador Allende.

Otro incentivo importante para la aplicación de técnicas conductuales fueron las visitas a inicios de la década de 1970 de Teodoro Ayllón y de Rubén Ardila, los que promovieron el uso de economía de fichas en poblaciones de pacientes psiquiátricos ${ }^{29}$. Estos programas representaron oportunidades inéditas de insertar la psicología en un ámbito que normalmente estaba reservado para la psiquiatría ${ }^{30}$. Esta demanda de inclusión de la psicología se ligaba directamente con "las transformaciones sociales que experimentaba la sociedad en su conjunto, y frente a la cual una gran mayoría de los psicólogos se sentían identificados, pero carentes de las herramientas necesarias para dar respuestas claras y adecuadas" ${ }^{31}$. Para Alejandro Dorna, otro de los factores que favorecieron la expansión del conductismo fue "la

\footnotetext{
${ }^{23}$ Ibidem, p.123.

24 Ídem, p.124.

25 Luco, Alfonso. 2010. La psicología en Chile, p.125.

26 Ídem, p.127.

27 Quezada, Vanetza; Vergés, Álvaro; Laborda, Mario. 2014. "Sergio Yulis", p.1.

28 Ídem, p.2.

29 Laborda, Mario; Míguez, Gonzalo; Quezada, Vanetza et al. 2019. "Notas para una historia".

${ }^{30}$ Vera-Villarroel, Pablo; Montesinos, Luis; Prieto, Arturo. 2010. "Historia del análisis".

31 Dorna, Alejandro. 1982. "La psicología del comportamiento”, p.149.
} 
insatisfacción creciente, en el medio clínico, por los enfoques clásicos de la psicoterapia y el carácter clasista que revestían dentro de la realidad chilena las diversas corrientes psicoterapéuticas en boga (psicoanálisis, gestalt, etc.)" 32 .

La experiencia y las investigaciones de Yulis también apuntaron al papel que le cabía al conductismo en el campo de la salud mental. Para él, la firme adscripción conductista a la metodología científica permitía diseñar técnicas eficientes, rápidas y económicas, que favorecerían la inserción de la psicología a los programas de salud mental. Tenía también la convicción de que la terapia conductista había surgido y se había desarrollado "motivada por el descontento con el statu quo anterior. Específicamente en lo que al área de salud mental se refiere" ${ }^{33}$. En su artículo "Terapia Conductual", desnuda las deficiencias de las "prácticas tradicionales" para implementar políticas de salud mental eficientes y "proporcionar una solución significativa a los pacientes denominados crónicos"34. También le parecen deficientes en "cuanto a evitar injusticias relacionadas con variables no clínicas tales como raza, educación, edad y clase social" ${ }^{35}$. Entre 1970 y 1973, Yulis fue profesor invitado de un programa de entrenamiento de expertos en salud pública organizado en conjunto entre la Organización de Estados Americanos y la Escuela de Medicina de la Universidad de Chile, lo que evidencia la proyección pública que se consideraba tenía el conductismo en ese momento.

En esta misma perspectiva es que a fines de la década de 1960, el psiquiatra Juan Marconi incorpora aplicaciones conductistas en los programas de salud mental comunitarios implementados en el área sur de Santiago, los que trataban con problemas como alcoholismo y estimulación preescolar "para los cuales la metodología conductual parecía ofrecer la mayor esperanza" ${ }^{36}$. Estos programas eran expresión de un proceso de cambio de la asistencia mental que venía gestándose en Chile desde mediados de siglo y que buscaba hacerse cargo de los cambios políticos y sociales que propugnaban una atención en salud mental social, democrática y comunitaria. Además, su desarrollo teórico y práctico, considerado revolucionario por el mismo Marconi, implicaba la constitución de un modelo comunitario de salud donde el médico no fuera el centro, sino un actor más ${ }^{37}$. La propuesta buscaba una superación del modelo médico hegemónico ${ }^{38}$.

\footnotetext{
32 Ídem.

${ }^{33}$ Yulis, Sergio. 1974. "Terapia del Comportamiento", en Revista Latinoamericana de Psicología, 6(3), Bogotá, pp.381402, p.382.

${ }^{34}$ Yulis, Sergio. 1974. "Terapia”, p.382.

35 Ídem.

${ }^{36}$ Vera-Villarroel, Pablo; Montesinos, Luis; Prieto, Arturo. 2010. “Historia del análisis", p.285.

${ }^{37}$ Araya, Claudia; Leyton, César. 2017. "La 'vía chilena' a la psiquiatría social. Propuestas y debates en torno al cambio de modelo de asistencia mental, 1968-1973", en Huertas, Rafael coord., Políticas de salud mental y cambio social en América Latina, Madrid, Catarata, pp.56-82.

${ }^{38}$ Entre 1970 y 1973, en la sede sur de la Facultad de Medicina de la Universidad de Chile, se realizaron una serie de trasformaciones en el currículo de los estudiantes de medicina dirigidos a acercarlo al modelo intracomunitario de
} 
Luego del golpe cívico-militar de 1973, el régimen de facto interrumpe el proceso de democratización que se venía desarrollando en las escuelas de psicología. En la Universidad de Chile, la carrera fue clausurada temporalmente y varios académicos adeptos al gobierno fueron expulsados, entre ellos profesores de orientación conductual, como Alejandro Dorna y Hernán Méndez ${ }^{39}$. Comenzó luego un progresivo debilitamiento y estancamiento de la investigación científica y de la perspectiva conductual. En la Universidad Católica, Yulis fue obligado a renunciar a su cargo de director y académicos cercanos a sus ideas fueron exonerados ${ }^{40}$. El conductismo debió enfrentar, a partir de ese momento, un "retroceso profundo, lo que provocó el fortalecimiento de otras corrientes. El psicoanálisis volvió a emerger como el enfoque predominante de la época" ${ }^{41}$. Según los mismos profesores, a diferencia de los psicoanalistas, los conductistas fueron perseguidos porque se los asoció con Pavlov, los rusos y los comunistas $^{42}$. Algunos académicos críticos del conductismo expresaron su simpatía por el nuevo gobierno, como Hernán Berwart Torrens en la Universidad Católica; y en la de Chile, Sergio Rey y Moisés Aracena ${ }^{43}$. Para el psicólogo Luis Montesinos, el conductismo fue considerado peligroso "porque obligaba a un análisis sistemático de las distintas variables responsables de ciertos fenómenos y a no aceptar dogmas y prejuicios, sino que la evidencia empírica. El uso del acercamiento científico era considerado peligroso y no tiene lugar dentro de un pensamiento totalitario" ${ }^{44}$.

salud. Se incluyeron las asignaturas de antropología cultural, sociología, psicología médica y semiología psiquiátrica. Los rectores militares impuestos por la Dictadura suprimieron esas asignaturas.

39 Quezada, Vanetza E.; Vergés, Álvaro; Laborda, Mario A. 2014. “Sergio Yulis", p.9.

40 Sergio Yulis partió al exilio, primero a Costa Rica y luego a Montreal, donde asumió la dirección del Servicio Psicológico del Hospital Royal Victoria del Allan Memorial Institute. También fue nombrado Profesor Asociado del Departamento de Psicología de la McGill University. Murió en Canadá en 1980.

${ }^{41}$ Laborda, Mario; Míguez, Gonzalo; Quezada, Vanetza et al. 2019. "Notas para una historia”, p.57.

42 Vera-Villarroel, Pablo; Montesinos, Luis; Prieto, Arturo. 2010. "Historia del análisis", p.287.

43 Quezada, Vanetza; Vergés, Álvaro; Laborda, Mario. 2014. "Sergio Yulis", p.9. Recién asumido como director, Berwart acusa al conductismo y a Yulis de "peligrosos". Camus, Pablo; Muñoz, Enrique. 2017. Psicología en la UC, p.68. Para Luis Montesinos, Berwart actuó como "el peor de los cobardes, fue un servil colaborador de la dictadura; ninguno de los profesores exonerados representaba un peligro para la sociedad chilena". Montesinos, Luis. 2019. Entrevista personal. En la Universidad de Chile, el psicólogo Moisés Aracena es recordado por algunos de sus colegas por su carácter hostil y persecutorio. Ligüeño, Sebastián; Parra, Diego; Moncada, Laura; Laborda, Mario. 2010. "La psicología en la Universidad de Chile: Antecedentes históricos y trayectoria de la carrera en el período 1947-1992", en Laborda, Mario; Quezada, Vanetza eds. Notas históricas, pp.27-54. Andrés Valenzuela, agente secreto de la Dictadura y torturador, participante en cientos de desapariciones, relata en 1984 a la periodista Mónica González, que fue atendido en una clínica psiquiátrica por Moisés Aracena, que "sabe todo" sobre su labor de agente secreto y "ha participado en contra subversión". En "Yo torturé", Revista Cauce, Separata, Año 2, N.32, 23-29 de julio de 1985, p.13. También acusa a Sergio Rey, psicólogo de la Universidad de Chile de atender a los torturadores del Servicio de Inteligencia de la Fuerza Aérea, como ayudante de Aracena.

${ }^{44}$ Montesinos, Luis. 2019. Entrevista. 


\section{Terapia de Economía de Fichas}

Al igual que Sergio Yulis, Juan Marconi se vio obligado a renunciar a la Universidad de Chile luego del Golpe Militar. En 1974 se fue de Chile, a la ciudad argentina de Córdoba, donde desarrolló un programa similar a los implementados en Chile ${ }^{45}$. Volvió al país y al Departamento de Psiquiatría y Salud Mental de la sede sur de la Facultad de Medicina de la Universidad de Chile en 1976, luego del golpe militar argentino. Había llegado ahí por primera vez en 1968 a organizar los primeros programas de salud mental intracomunitaria, donde la vinculación entre el departamento y la comunidad tuvo un papel fundamental. Basado en esa vinculación, Marconi establece tres etapas históricas del desarrollo de la salud mental en el área sur de Santiago. Entre 1968 y 1973 ocurre la integración entre la comunidad del área sur y el Departamento. En la segunda etapa, de 1974 a 1980, "el hecho capital es la pérdida abrupta de la inserción comunitaria del Departamento" ${ }^{46}$; aun cuando, persiste una integración entre los académicos del departamento y el Servicio de Salud Mental sur. Uno de los logros de esta asociación fue la refundación, en 1976, del Hospital Psiquiátrico El Peral. Finalmente, en la tercera etapa, de 1980 a 1990, se constata un "aislamiento progresivo, no solo de las raíces comunitarias del Departamento, sino de su proyección institucional en los Servicios de Salud Mental del Área Sur"47.

En 1976, como parte del proceso de refundación, el Hospital Psiquiátrico El Peral firmó un convenio con el Departamento de Psiquiatría y Salud Mental de la sede sur de la Facultad de Medicina de la Universidad de Chile. El convenió permitió la implementación de un programa de psicofarmacología clínica y otro de rehabilitación de pacientes crónicos basado en las teorías del aprendizaje. Según el Censo de Hospitalizados en Establecimientos Psiquiátricos de 1976, más del $78 \%$ de las camas psiquiátricas del sistema público de salud se concentraban entre el Hospital Psiquiátrico El Peral y el Hospital Psiquiátrico de Putaendo. De estos pacientes, dos tercios eran de larga estadía, con más de dos años de hospitalización y, aproximadamente un cuarto de ellos había permanecido internado por veinte años o más ${ }^{48}$. Lo que configuraba, junto a la escasez de recursos y a la miseria ambiental, "un cuadro que no es menos que patético" ${ }^{49}$.

\footnotetext{
${ }^{45}$ Marconi, Juan. 1974. "Diseño de un programa integral de salud mental para la ciudad de Córdoba", en Acta Psiquiátrica y Psicológica de América Latina, Vol. 20, № 3, Buenos Aires, pp.240-246.

${ }^{46}$ Marconi, Juan. 1998. Del asilo a la comunidad, p.39.

47 Ibídem, p.38.

48 Trucco, Marcelo. 1976. "Censo de hospitalizados en establecimientos psiquiátricos de 1976". Documento informativo del Minsal, Unidad Técnico Normativa, Departamento de Programa de las personas, en Archivo de la Administración, Fondo Ministerio de Salud, Santiago.

49 Montesinos, Luis; Bravo, Laura; Tedias, Miriam; Jara, Rosa; Peralta, María Inés; Álvarez, Ruth; Ríos, Cristina; Miranda, Sara; Álvarez, María Inés; Zanghellini, Germán. 1978. "Rehabilitación de pacientes mentales crónicos: Una combinación del esquema de delegación de funciones con las técnicas del condicionamiento operante", en Acta Psiquiátrica y Psicológica de América Latina, Vol. 24, Buenos Aires, p. 35.
} 
El único documento sobre políticas ministeriales fue publicado en agosto de 1978. Allí se propone erradicar "al máximo el ambiente asilar que aún persiste, mediante diversos sistemas de rehabilitación"; para, en el largo plazo, "reducir paulatinamente el número de camas en los hospitales psiquiátricos de larga estada" ${ }^{50}$. Sin embargo, más que una política pública, opera como una declaración de intenciones. No hay ningún plan o programa asociado a ese documento. Según Marconi, la política de salud mental durante la dictadura militar fue "totalmente trastocada... no pasó nada, absolutamente nada..., se volvió a la atención psiquiátrica tradicional; todos los recursos se destinaron para allá" 51 .

Antes del golpe cívico-militar, el modelo integral de salud mental era la propuesta que estaba en el centro del debate. En 1976, luego del desmantelamiento de los programas intracomunitarios y la inviabilidad política del modelo integral, Marconi propone, como alternativa, la implementación de programas integrales intermedios de "bajo costo, de acelerada difusión, de dinámica interna alta, que utilice recursos locales" ${ }^{\prime 2}$. Se esperaba que el Hospital Psiquiátrico El Peral se transformara en una unidad de salud mental que incluyera, además del Hospital, una red de consultorios periféricos y de hogares protegidos para pacientes crónicos. El objetivo de esta unidad de salud mental sería reducir al mínimo la hospitalización completa, ya sea a través de consulta externa, hospital diurno, taller de rehabilitación, educación de la comunidad, docencia o investigación.

Luego de la firma del convenio entre El Peral y el Departamento de Psiquiatría y Salud Mental de la Facultad de Medicina de la Universidad de Chile, en 1976 comienza a diseñarse el proceso de refundación del hospital. Se crea un servicio de pacientes agudos y se convoca a un nuevo equipo de dirección y profesionales de diversas áreas para hacerse cargo de la rehabilitación de los enfermos crónicos. La propuesta general consistía en transformar el Sanatorio El Peral en un "centro de rehabilitación sectorizado", vinculado a un "complejo de salud mental organizado de acuerdo al modelo integral" ${ }^{53}$. Lo que significaba en la práctica, implementar, por primera vez en dictadura, un Programa de Salud Mental en el área sur de Santiago ${ }^{54}$; que pretendía, además, una continuidad con los programas de psiquiatría comunitaria desmantelados inmediatamente instalado el régimen militar.

\footnotetext{
${ }^{50}$ Ministerio de Salud. 1978. "Políticas de Salud Mental", en Archivo de la Administración, Fondo Ministerio de Salud, Santiago, pp. 17-18.

${ }^{51}$ Mendive, Susana. 2004. "Entrevista al Dr. Juan Marconi, creador de la psiquiatría intracomunitaria. Reflexiones acerca de su legado para la psicología comunitaria chilena", en Psykhe, Vol 13, №2, Santiago, pp.187-199, p.194.

52 Marconi, Juan. 1976. "Política de salud mental en América Latina”, en Acta Psiquiátrica y Psicológica de América Latina, Vol.22, №4, Buenos Aires, p.116.

53 Zanguellini, Germán. 1977. Antecedentes Históricos, p.5.

${ }^{54}$ Barraza, Fernando. 1977. "No hay salud mental sin trabajo social: nuevos enfoques en los programas de salud mental subrayan el papel protagónico del trabajador social. Entrevista al doctor Alfredo Pemjean y al psicólogo Rafael Estévez", en Revista de Trabajo Social, №23, Santiago, p.38.
} 
Juan Marconi contactó al psicólogo Luis Montesinos para que se hiciera cargo del programa de rehabilitación de crónicos ${ }^{55}$. Según Montesinos, Marconi "tenía un tremendo ascendiente intelectual sobre lo que ocurría en los programas de salud mental en el Área Hospitalaria Sur" 56. Solo pudo ofrecerle "una posición como psicólogo del Servicio Nacional de Salud con un sueldo escaso", pero:

"pudo más la motivación por intentar hacer psicología con sentido público, psicología con y para los abandonados, los dispensables. Esto era precisamente lo que proponía el Prof. en los tiempos de la dictadura este lugar daba la posibilidad de hacer cosas concretas en un tiempo en el que volar estaba prohibido" ${ }^{57}$.

El plan que Marconi le describió fue transformar el hospital Sanatorio El Peral desde un modelo asilar a uno integral ${ }^{58}$. La finalidad sería "egresar, en un mediano plazo, dos tercios de los 1.200 niños, mujeres y hombres internos en la institución" ${ }^{59}$. Se esperaba aplicar la estructura del mismo programa intracomunitario que Marconi y su equipo habían desarrollado con éxito entre 1968 y 1973, vinculado esta vez a terapias conductistas. Alberto Minoletti, quien fue parte del equipo de Marconi, recuerda sus "cuestionamientos a las terapias psicoanalíticas y sus enseñanzas innovadoras sobre las terapias conductuales, en los albores de Eysenck y Wolpe, terapias que 40 años más tarde se profundizaron y generalizaron" ${ }^{60}$. Según Montesinos:

"a pesar de que él [Marconi] nunca se declarase conductista, sus acciones claramente indicaban que veía en el conductismo el potencial teórico y técnico para desarrollar programas comunitarios que fuesen exitosos [...] entendía que la meta central era el cambio de conducta permanente y para ello había que utilizar un acercamiento que fuese efectivo, eficiente y empíricamente evaluado, esto era lo que el conductismo representaba para él" 61 .

\footnotetext{
55 Mientras Luis Montesinos estudiaba psicología en la Universidad Católica siguió el curso de Sergio Yulis, Técnicas de Tratamiento Psicológico, del que Miren Busto era ayudante. En esa instancia escribió una traducción crítica del libro de Ayllon y Azrin, Token Economy, publicado por primera vez en 1968.

${ }^{56}$ Montesinos, Luis. 2018. "Intervención cultural”, p.3.

57 Ibídem, p.3.

58 El mismo Montesinos había desarrollado un Programa de Economía de Fichas para el Patio 9 del Instituto Psiquiátrico, el que no alcanzó a implementarse, producto del Golpe Militar de 1973. Cuarenta años después de la intervención en El Peral, recuerda que a pesar de que no alcanzaron ni siquiera a iniciar el programa en el Instituto Psiquiátrico, la experiencia le sirvió para familiarizarse con el mundo asilar, "tan fuera de los márgenes de la sociedad formal, que imperaba en ese recinto". En Montesinos, Luis. 2018. "Intervención cultural”, p.3.

59 Montesinos, Luis. 2018. "Intervención cultural”, p.3.

60 Minoletti, Alberto. 2006. "Semblanza Juan Marconi Tassara”, en Revista Chilena de Neuropsiquiatría, 44(1), Santiago, pp.61-62, p.62.

${ }^{61}$ Montesinos, Luis. 2019. Entrevista.
} 
Si bien es cierto que, como señalan Magaña y Loubat, los programas intracomunitarios de Marconi aludían conceptualmente a una apertura psico-social-comunitaria, esta apertura no se tradujo en "el acceso de la psicología en este proyecto público" ${ }^{62}$. En ese sentido, el proyecto de rehabilitación del Hospital Psiquiátrico El Peral representaba tanto una manera de continuar la propuesta de salud mental comunitaria interrumpida con el Golpe, como la incorporación de la psicología al campo de la salud mental, en un momento de gran represión, cuando "las posibilidades de formular proyecciones eran casi nulas" y la psicología chilena solo podía "centrar sus esfuerzos en la subsistencia" ${ }^{63}$.

Luis Montesinos asumió como director técnico y el psiquiatra Germán Zanghellini como director administrativo. Aunque el programa contó con el apoyo institucional del Servicio de Salud Metropolitano Sur, fue necesario recolectar fondos a través de campañas televisivas, lo que da indicios de la precarización que comenzaba a afectar al sistema de salud chileno. El equipo quedó conformado por un psicólogo, una asistente social, un psiquiatra, cuatro estudiantes de psicología, una jefa de pabellón y quince auxiliares de planta ${ }^{64}$. Avanzado el programa, estudiantes de último año de psicología de la Universidad Católica hicieron sus tesis de grado sobre la efectividad del condicionamiento operante en el control de la conducta verbal ${ }^{65}$. Se formó un grupo que se reunía, discutía, publicaba y asistía a conferencias. Para los integrantes, "contar con técnicas efectivas y eficientes era un mandato ético y eso se respiraba en esas reuniones" 66 .

Como la meta a mediano plazo era desarrollar el modelo integral, se decidió implementar como programa de rehabilitación el Programa de Economía de Fichas (PEF) ${ }^{67}$, que era "visto como esencial por el Profesor Marconi [...], un programa que a través de diferentes etapas lograría retornar a la comunidad el mayor número posible de pacientes mientras a la vez ofreciera un nivel de activación saludable y digno para los que tendrían necesariamente que

\footnotetext{
62 Magaña, Irene; Loubat, Margarita. 2010. “Psicología, salud mental y salud pública: Una mirada panorámica histórico-crítica", en Laborda, Mario; Quezada, Vanetza eds. Notas históricas, pp.193-213, p.201.

63 Laborda, Mario; Míguez, Gonzalo; Quezada, Vanetza et al. 2019. “Notas para una historia”, p.53.

64 Montesinos, Luis. 1976. "Sub-Programa de Rehabilitación Hospital Psiquiátrico Puente Alto. Un programa de Economía de Fichas para el Patio 10", en Archivo Hospital Psiquiátrico El Peral, Serie Documentos Históricos, Santiago, pp. 8.

${ }^{65}$ Aguayo, Enrique; García, Jorge; Ugalde, Francisco. 1977. Uso del condicionamiento operante para modificar la conducta verbal en pacientes psiquiátricos crónicos. Un estudio de casos, Pontificia Universidad Católica de Chile, Tesis para optar al título de psicólogo.

${ }^{66}$ Montesinos, Luis. 2018. "Intervención cultural”, p.5.

67 Para algunos autores, la mayor dificultad de los pacientes crónicos no está en la sintomatología psicótica, sino en que su repertorio conductual no es considerado por la comunidad externa como adaptativo. La inadaptación social persiste aun con tratamientos farmacológicos efectivos, por lo que la inclusión de terapias conductuales resulta ría fundamental para el desarrollo de comportamientos adaptativos. Particularmente los "sistemas de fichas", representan la alternativa más eficiente al tratamiento tradicional de los pacientes psiquiátricos. Roales-Nieto, Jesús; Fernández, Antonio. 1986. "La Economía de Fichas en el tratamiento de pacientes crónicos: el papel del personal institucional”, en Revista Latinoamericana de Psicología, Vol.18; №1, Bogotá, pp.23-41, p.26.
} 
permanecer institucionalizados. El programa proveía la tecnología necesaria para hacer posible el cambio"68. El PEF quedó definido como una combinación de las técnicas de la modificación de la conducta, en este caso concreto el fortalecimiento operante (FO), con el esquema de delegación de funciones (EDF), "en la hipótesis de que su aplicación conjunta será más efectiva" ${ }^{69}$.

La "pirámide" o EDF, ya había sido parte importante de los programas intracomunitarios implementados en el área sur de Santiago y definido por el mismo Marconi como el "paso de conocimiento en forma masiva desde los investigadores teóricos universitarios hacia la comunidad"70. En el EDF, el conocimiento se traspasa a través de unidades de adiestramiento ${ }^{71}$. La combinación de modificación conductual con EDF multiplica el efecto terapéutico de una sola persona, a la vez que entrena a los distintos niveles de la pirámide en tareas de rehabilitación. Este Esquema de Delegación representaba para los impulsores del PEF un aporte del pasado, una experiencia identitaria, eficiente, social y que enriquecía las técnicas conductuales. Cuando Marconi analiza, hacia fines del siglo pasado, los aportes de los programas intracomunitarios y del EDF, destaca como uno de sus principales, su carácter de investigación-acción, que permitía que los sujetos (no pacientes) participaran en el proceso teórico y práctico de su rehabilitación.

Primero se establecieron los cincos niveles de delegación (D1 a D5) de la pirámide (EDF), apropiados para la situación ${ }^{72}$. Luego, se montó un sistema de entrenamiento que dotara a los cinco niveles establecidos de las técnicas necesarias para su funcionamiento como agente rehabilitador. En el nivel D1 se encontraba un psicólogo con formación conductual, cuya función era crear los procedimientos que posibilitaran la aparición de comportamientos adecuados y su consecuente reforzamiento. Debía entregar información y entrenamiento a los distintos niveles para lograr el cambio conductual deseado. El nivel D2, ocupado por un psiquiatra, dos terapeutas ocupacionales y dos asistentes sociales entrenados en técnicas conductuales, encargados de reforzar conductas específicas logradas por el Programa. El nivel D3 correspondía a personal auxiliar y de servicio, con la función de reforzar conductas, entrenar a los sujetos y supervisar el trabajo de los D4. En el nivel D4 se ubicaban los pacientes con un repertorio conductual de nivel adecuado, mientras que, en la base de la pirámide (nivel D5), los

\footnotetext{
68 Montesinos, Luis. 2019. Entrevista.

${ }^{69}$ Montesinos, Luis; Bravo, Laura; Tedias, Miriam et al. 1978. "Rehabilitación de pacientes mentales crónicos", p.36.

70 Mendive, Susana. 2004. "Entrevista al Dr. Juan Marconi", p.188.

71 Juan Marconi atribuye a Vicente Silva, médico chileno educador en salud, la creación e implementación en puericultura y pediatría de las unidades de adiestramiento. Mendive, Susana. 2004. "Entrevista al Dr. Juan Marconi”, p.188.

72 Para una comprensión adecuada del esquema de delegación de funciones ver Marconi T., Juan. 1973. "La revolución cultural chilena en programas de salud mental", en Acta Psiquiátrica y Psicológica de América Latina, Vol. 19, Buenos Aires, pp.17-33.
} 
pacientes a tratar. Lo que se esperaba era que "hubiese una movilidad hacia arriba en el esquema y que muchos D2 pasaran a ocupar el nivel D1", lo que se "logró con creces" y permitió "la implementación de programas de rehabilitación en otros pabellones y ambientes del Hospital"73.

Para Montesinos, las bases teóricas del Programa correspondían a los principios del Condicionamiento Operante (Skinner, 1953) y particularmente a los del reforzamiento ${ }^{74}$. La técnica del Fortalecimiento Operante corresponde al "análisis funcional del comportamiento de un determinado organismo, en relación a los eventos ambientales que le rodean, a través del cual es posible establecer relaciones funcionales que permitirán controlarlo y predecirlo de manera confiable"75. Su objeto de estudio es "el comportamiento que es observado y medido en su tasa de emisión", a partir de lo cual es posible categorizarlo como excesivo, adecuado o deficitario ${ }^{76}$. Otro referente fue la obra de Teodoro Ayllon y Nathan Azrin, donde se recoge la experiencia de seis años de aplicación masiva del condicionamiento operante, a través de un Programa de Economía de Fichas ${ }^{77}$. Para los autores, el paciente de larga evolución, producto de la institucionalización, presenta excesos y déficits en su comportamiento, que le impiden vivir en comunidad. Por lo tanto, los objetivos se orientaron a mantener los comportamientos adquiridos no solo a lo largo del tiempo, sino también en diferentes ambientes.

Además de los aspectos técnicos, Luis Montesinos resalta la motivación que impulsó la implementación del Programa, la que "tenía que ver con el contexto histórico del país, con nuestra ideología, con muchas cosas. [...] Teníamos un programa que funcionaba siete días a la semana veinticuatro horas al día. Una economía de fichas no funciona si no es asi" ${ }^{78}$. Las primeras visitas de diagnóstico del equipo al hospital: "fueron aterradoras: pacientes hacinados, tendidos en el piso de los pabellones, rodeados de sus propias deposiciones [...] configurando un establo humano; desnutrición masiva de los enfermos [...] con uno o más cadáveres a la llegada [...] altísima morbilidad psiquiátrica de los médicos; muchos de ellos asilados crónicos, al igual que sus pacientes"79. El Hospital Psiquiátrico El Peral era en ese entonces "un verdadero matadero social, como una pensión sin propósito, un depósito de

\footnotetext{
73 Montesinos, Luis. 1979. "Informe final de la aplicación de un Programa de Economía de Fichas en combinación con el esquema de delegación de funciones, en la rehabilitación de pacientes psiquiátricos crónicos [documento inédito]", Cuadernos de Salud Mental, Psiquiatría y Psicología, Departamento de Salud Pública, Salud Mental y Psiquiatría, Facultad de Medicina Sur, Universidad de Chile, p.4

${ }_{74}$ Montesinos, Luis. 1976. "Sub-Programa de Rehabilitación".

75 Montesinos, Luis. 1979. "Informe final", p.2.

76 Ídem.

77 Ayllon, Teodoro; Azrin, Nathan. 1968. The Token Economy. A Motivational System for Therapy and Rehabilitation, New York, Meredith Corporation.

78 Luco, Alfonso. 2010. La psicología en Chile, p.118.

79 Marconi, Juan. 1998. Del asilo a la comunidad, p.46.
} 
enfermos que se morían de frío en las noches de invierno" 80 . Durante las mañanas, el pabellón de niños "cobraba ribetes dantescos, algunos deambulaban desnudos y sucios con excrementos [...] otros lloraban de hambre después de alrededor de 12 horas de ayuno [...], la muerte se paseaba sin ropas" 81 . Para Luis Montesinos: "todo pareciera estar sistemáticamente planificado para que los sujetos pierdan el escaso contacto que mantienen con la realidad y se suman en una pesadilla que solo terminará el día de su muerte"; aun cuando existían algunas actividades, no tenían un sentido terapéutico, más bien estaban orientadas "a permitirle al residente (paciente) un mejor pasar o porque no decirlo en otros casos a explotar una mano de obra barata" 82 .

El Programa de Economía de Fichas se inició en el Pabellón 10, donde residían los pacientes de más bajo nivel conductual. Se seleccionó a 31 sujetos, para pronto incluir a los 150 que ocupaban el pabellón ${ }^{83}$. Se programó un repertorio de conductas adaptativas relevantes para la futura vida en comunidad, lo que se conoce como "Regla de la Relevancia del Comportamiento (Ayllon y Azrin, 1965), y consiste en instaurar conductas que continuarán siendo reforzadas una vez que el sujeto abandone el establecimiento" ${ }^{84}$. Una vez definidas las conductas relevantes para la vida en comunidad, se programaron rutinas de reforzamiento para todos los días de la semana, durante todo el día. Las rutinas fueron implementadas, reforzadas y supervisadas por el personal de apoyo, el que fue entrenado en las técnicas del Fortalecimiento Operante. Para cada uno de los comportamientos se diseñó una pauta simple de registro. Para la manipulación de los eventos ambientales previos y posteriores al comportamiento, se programaron una serie de cambios físicos que hicieran más probable la aparición de determinados comportamientos. Así, se fijaron lugares para la realización de las actividades, se construyó una tienda y se separó a los pacientes del Programa del resto de los internados, en cuanto a dormitorio y comedor. "Se los dotó de ropa adecuada y de elementos mínimos (ique no existían!) como cucharas, máquinas de afeitar, peinetas, etc." ${ }^{85}$.

Después de la observación basal se introdujeron los reforzadores tangibles, los que posteriormente se cambiaron por fichas que permitían adquirir los artículos en la tienda. Además de productos como cigarrillos y objetos de uso personal que se adquirían en la tienda, las fichas podían canjearse por elección de una pieza o acceso a la sala de televisión ${ }^{86}$. Los

\footnotetext{
80 Mendive, Susana. 2004. "Entrevista al Dr. Juan Marconi", pp.193-194.

81 Montesinos, Luis. 2018. "Intervención cultural”, p.4.

82 Montesinos, Luis. 1979. "Informe final", p.1.

83 Se buscó que algunos de los 31 pacientes seleccionados poseyeran un repertorio comportamental más amplio, para que ocuparan rápidamente algún lugar en D4. También se incluyeron otros sujetos extremadamente deteriorados para ver cómo el Programa de Economía de Fichas afectaba su comportamiento.

${ }^{84}$ Montesinos, Luis. 1979. "Informe final”, p.2.

85 Ibídem, p.3.

${ }^{86}$ Montesinos, Luis. 1976. "Sub-Programa de Rehabilitación”, páginas sin numerar.
} 
procedimientos instaurados fueron actividad física; afeitada; aseo personal; baño; hacer su propia cama; presentación personal; comportamiento verbal y comportamiento laboral ${ }^{87}$. Se hizo un énfasis especial en este último, aumentando los tipos de trabajo, las vacantes, el número de horas y la integración de labores más complejas que se asemejaran más a las actividades de trabajo en el exterior. La efectividad del programa se vinculó estrechamente con la conducta de los auxiliares encargados de aplicarlo. Tuvo que convencérselos de "la real posibilidad de cambiar el comportamiento de los pacientes y de que su propio comportamiento podía hacer una diferencia" ${ }^{\prime 8}$.

Para un Programa de este tipo, que no opera -según Luis Montesinos- con la lógica del modelo médico psiquiátrico, lo relevante no es la etiología sino las condiciones del paciente. Lo que implica que la función del auxiliar del pabellón ya no puede limitarse a darle las pastillas al paciente, sino que debe interactuar constantemente con él y mantenerse atento a las conductas adecuadas para reforzarlas. Es decir, se transforma en "un agente de cambio", lo que es muy diferente a lo que "ha estado haciendo en los últimos veinte o treinta años" 89 . Siguiendo esta "ética de trabajo" y "compromiso con los pacientes" el personal auxiliar se comprometió con el programa ${ }^{90}$. Algunos estudios mostraban que el comportamiento del personal estaba mucho más de acuerdo con una orientación de custodia que con una de rehabilitación, "en el sentido que tienden a mantener el 'repertorio anormal' de los sujetos" ${ }^{\prime \prime}$. Otros muestran lo contrario, un refuerzo positivo. Por esto, como parte del PEF, Montesinos junto al psicólogo Jorge García, instalaron un programa destinado a seis auxiliares de apoyo del Pabellón 10. Después de un mes de supervisión, el comportamiento rehabilitador se estaba ejecutando a un alto nivel, pero con algunas variables difíciles de asimilar ${ }^{92}$.

A medida que la rutina del programa de fichas fue estableciéndose y que el personal entrenado pudo ocupar los distintos niveles del EDF, se implementaron nuevos programas que Ilegaron finalmente a cubrir todo el Pabellón 10, como el Programa de Patio, el Programa de Niños y el Programa de Control de Esfínteres ${ }^{93}$. A continuación, se inició el trabajo para insertar en la comunidad a los residentes que habían alcanzado un nivel conductual que "permitiera

\footnotetext{
87 Ibídem, p.27.

88 Montesinos, Luis. 2018. "Intervención cultural”, p.5.

89 Luco, Alfonso. 2010. La psicología en Chile, p.120.

90 Montesinos, Luis. 2018. "Intervención cultural”, p.5.

91 García, Jorge; Montecinos, Luis. 1979. "Uso de técnicas de condicionamiento operante en la instauración y mantención de conductas rehabilitadoras en el personal de apoyo", en Revista Chilena de Psicología, 1, Santiago, pp.19-30, p.20.

92 El equipo del Programa de Economía de Fichas se reunía semanalmente para presentar y analizar distintas iniciativas dentro del área. Una de ellas, "Entrenamiento de Personal en Técnicas de Condicionamiento Operante a través de un esquema de delegación de funciones", fue presentada en las Primeras Jornadas de Entrenamiento de Personal, en la Facultad de Medicina Sur de la Universidad de Chile, en 1977. Montesinos, Luis. 2019. Entrevista. ${ }^{93}$ Montesinos, Luis. 1979. "Informe final”, p.36.
} 
predecir que serían capaces de vivir fuera del asilo". Con este fin se habilitaron ambientes físicos "que simulaban una casa de clase media baja y en él participaban los familiares que recibirían al residente una vez que se diera el alta" ${ }^{94}$. Uno año después el Programa se extendió a todo el Hospital. En marzo de 1977 se creó el servicio de alta, "de 20 pacientes entrenados con repertorio laboral y social, salieron a casa de familiares $17 " 95$.

Otro de los problemas que atentaba contra las altas era la baja proporción de internos que tenían familia para recibirlos. Para Montesinos, "las frecuentes readmisiones, traslados y la categoría de irrecuperable aplicada por uno o varios profesionales refuerzan en los familiares la idea de que el sujeto está incapacitado para vivir en la comunidad y que deberá permanecer recluido por el resto de su vida. Esto hace que muchos núcleos pierdan contacto con sus miembros enfermos y los abandonen"96. Los pacientes que no podían retornar con sus familias se instalaron en hogares-talleres protegidos que estaban en contacto con las diferentes agrupaciones de la comunidad en la que se insertaron. Se esperaba que, en el futuro, estos "agentes naturales de la comunidad", fueran "informados y entrenados para reforzar las conductas adecuadas que poseen los diferentes sujetos, en sus repertorios" ${ }^{\prime 97}$. En 1978, cuando el PEF ya llevaba dos años, la resistencia inicial había disminuido. En palabras de Luis Montesinos, se había "logrado reclutar un buen número de auxiliares de enfermería nuevos y persuadir a algunos de los más resistentes a través de los resultados obtenidos y de una ética laboral que demostraba claramente nuestro compromiso no solo con el bienestar de los pacientes, sino que con el de ellos también" ${ }^{\prime 98}$.

En 1979, el Departamento de Psiquiatría y Salud Mental de la sede sur de la Facultad de Medicina de la Universidad de Chile publicó la evaluación del PEF, con una introducción de Juan Marconi, donde sostiene que "lo hecho en esos dos años, es una tarea que sólo merece calificarse como heroica, queda como prueba de lo correcto del diseño global, y de la efectividad de la combinación de las técnicas de reforzamiento operante y de los principios del Programa Integral"99. En el documento se resalta el uso combinado del Fortalecimiento Operante y el Esquema de Delegación de Funciones como un procedimiento "efectivo para modificar en un alto número de residentes una variedad de comportamientos [...] efectuando en ellos cambios clínicos relevantes para su reinserción en la comunidad" ${ }^{100}$. Además de una

\footnotetext{
94 Montesinos, Luis. 2018. "Intervención cultural", p.5. El Archivo fotográfico del Hospital Psiquiátrico El Peral conserva una fotografía de esta casa modelo.

95 Marconi, Juan. 1998. Del asilo a la comunidad, p.47.

96 Montesinos, Luis. 1979. "Informe final”, p.35.

97 Montesinos, Luis; Bravo, Laura; Tedias, Miriam et al. 1978. "Rehabilitación de pacientes mentales crónicos", p.39.

98 Montesinos, Luis. 2019. Entrevista.

99 Montesinos, Luis. 1979. "Informe final”. El prólogo no numerado del Informe fue escrito por el Dr. Juan Marconi.

100 Montesinos, Luis. 1979. "Informe final", pp.39-40. Para los autores, la forma adecuada de verificar esta hipótesis sería a través de un estudio que comparara un grupo control, con un grupo de economía de fichas y con un tercer
} 
alterativa válida y de aplicación masiva, representaba un bajo costo económico ${ }^{101}$. Estos resultados plantearon a los autores un problema más ético que tecnológico: ¿Cómo permitir que los asilos sigan existiendo si se cuenta con la tecnología adecuada para modificar el comportamiento, con buenos resultados y a un bajo costo ${ }^{102}$.

Ese y otros "problemas" se resolvieron de manera abrupta, como han sido los devenires de los procesos de salud mental en el Chile del siglo XX. Hacia fines de 1978, el PEF debió cerrarse. Según Marconi, "la dictadura olió algo y se cortó el programa" ${ }^{103}$. Denuncia que desde ese mismo año de 1978 había comenzado a recibir "mensajes verbales y trascendidos, anunciando acciones amenazantes" si permanecía en la Universidad de Chile. En 1979 fue intervenido el Departamento de Psiquiatría y Salud Mental, inicialmente por el propio decano, que paralizó la institución durante meses y luego por un pediatra "de triste desempeño en una tarea sucia de verdugo, decapitando al grupo académico con maniobras oscuras, traslados, amenazas de relegación a otras instituciones, descalificación pública" ${ }^{104}$. En marzo de 1980, Marconi decide renunciar a su cargo de Profesor Titular de la Universidad de Chile.

Persistía, sin duda, un problema político profundo. Un Programa de este tipo, con apoyo institucional, no podía subsistir en un contexto de violencia estatal como el que vivía el país en ese momento. Hablar de rehabilitación de enfermos mentales cuando la Dictadura asesinaba y desaparecía personas, no presenta coherencia alguna. Sobre los problemas internos en la aplicación del programa, la misma evaluación del proceso había establecido que era necesaria una redefinición de las metas y los objetivos de la dirección del hospital respecto a la rehabilitación y la participación de la comunidad. La estructura fundamentalmente asilar que seguía manteniendo el Hospital Psiquiátrico El Peral, dejaba claro que "implantar un programa de rehabilitación en medio de un asilo traerá consigo inevitablemente choques entre la orientación técnica y la estructura administrativa anquilosada que existe en este tipo de establecimientos" 105 .

Para Luis Montesinos, el problema "no fue técnico, fue político, ideológico. Se vivían tiempos muy raros en Chile el año 1978. [...] Ascendía gente a posiciones de poder sin tener las calificaciones para estar en esa situación y tomaban decisiones que no correspondían" ${ }^{106}$. Al año siguiente, en 1979 , se nombra un director subrogante que paralizó la mayoría de los

\footnotetext{
grupo de economía de fichas con esquema de delegación. Sin embargo, se desecha esa posibilidad ante la necesidad de soluciones prontas y efectivas para personas que se encuentran con un importante deterioro.

101 En 1978, el presupuesto general de rehabilitación del Hospital Psiquiátrico El Peral fue de $\$ 30.000$. De estos, apenas alrededor de $\$ 2.000$ a \$3.000 se ocuparon en el Programa de Economía de Fichas. Caballero, María Soledad; Liberman, Lucía. 1980. Estudio diagnóstico, p.185.

102 Montesinos, Luis. 1979. "Informe final”, p.40.

103 Mendive, Susana. 2004. “Entrevista al Dr. Juan Marconi”, pp.193-194.

104 Marconi, Juan. Del asilo a la comunidad, p.53.

105 Montesinos, Luis. 1979. "Informe final", p.37.

106 Luco, Alfonso. 2010. La psicología en Chile, p.119.
} 
programas de rehabilitación que se encontraban funcionando en El Peral en ese momento ${ }^{107}$. Los profesionales, que se habían capacitado en las técnicas del análisis y modificación conductual, renunciaron masivamente lo que significó la pérdida del eje programático. También se perdió todo contacto con la burocracia del Hospital, por lo que no hubo posibilidad alguna de seguimiento. El equipo dejó "de tener acceso a sus fichas médicas o información acerca de donde vivían"108. El retiro de los refuerzos tangibles (fichas) no ocurrió de manera gradual y planificada, por lo que se veían "pacientes que emitiendo las conductas esperadas ya han juntado 5.000 puntos o más, sin poder canjearlos por ningún reforzador concreto" ${ }^{109}$. Los pacientes quedaron en un estado de deterioro que fue progresando hasta fines del siglo pasado.

El año 2010, en una entrevista que se le hace a Montesinos sobre la experiencia del Programa de Economía de Fichas, lo reconoce como:

"un hito histórico, [...] una experiencia muy importante, pero si miro los hospitales psiquiátricos hoy, las cosas no han cambiado mucho. La economía de fichas es el tratamiento de elección en este tipo de situaciones, eso está claramente establecido. Pero que hayamos logrado cambiar la percepción de la jerarquía que estos pacientes ocupan en los presupuestos fiscales, eso no lo logramos. [...] El abandono es total, de los familiares, de las instituciones, es un desamparo total" ${ }^{\prime 10}$.

Mientras se realizaba el Programa de Economía de Fichas, un equipo de psicólogos, con la participación de Luis Montesinos, dirigidos por Alfonso Luco, realizaron un video sobre esa experiencia, que titularon Pabellón 10, $1977^{111}$. En él se da a entender que el programa tuvo que descontinuarse por diferencias entre el equipo técnico formado por psicólogos y la dirección del Hospital dirigida por psiquiatras, en el momento en que el Programa pretendía extenderse a los 4.000 pacientes crónicos del sistema de salud nacional. Para la grabación del video se utilizaron fotografías que se habían realizado antes de comenzar el PEF, con el fin de recaudar fondos en Inglaterra. Terminada la experiencia se tomaron otras fotografías para evidenciar el éxito del Programa ${ }^{112}$.

\footnotetext{
107 Caballero, María Soledad; Liberman, Lucía. 1980. Estudio diagnóstico, p.170.

108 Montesinos, Luis. 2019. Entrevista.

${ }^{109}$ Caballero, María Soledad; Liberman, Lucía. 1980. Estudio diagnóstico, p.198.

110 Luco, Alfonso. 2010. La psicología en Chile, p.118.

111 Luco, Alfonso. 1977. Pabellón 10, [citada 9 ago 2020]. Disponible en: https://www.youtube.com/watch?v=uvqedWhQiBs.

112 Las fotografías se conservan en el Archivo del Hospital Psiquiátrico El Peral, serie Fotografías. Para un acercamiento a las colecciones fotográficas del Hospital ver Araya, Claudia; Morales, Nicolás; Leyton, César. 2020. "Archivo del Hospital Psiquiátrico El Peral: una experiencia de investigación desde la historia cultural de la psiquiatría", en Revista de Historia Social y de las Mentalidades, Vol 24, № 1, Santiago, pp.147-168.
} 


\section{Conclusiones}

El Programa de Economía de Fichas fue un plan de rehabilitación de pacientes crónicos institucionalizados del Hospital Psiquiátrico El Peral, implementado entre 1976 y 1978. Su diseño y aplicación se basó en la combinación de técnicas de aprendizaje conductista con un sistema de delegación de funciones que permitía la inclusión progresiva de toda la comunidad en el proceso de rehabilitación. Tiene su origen en procesos sanitarios y de cambios políticos y sociales que venían generándose desde fines de la década de 1960 en Chile. Por una parte, los programas intracomunitarios de salud mental, que se llevaron a la práctica entre 1968 y 1973 , que incluían esquemas de delegación de funciones y a través de los cuales comenzaba a posicionarse la salud mental en Chile. Y, por otra parte, el conductismo, que había llegado a las universidades de la mano de procesos de cambio político profundo, contribuyendo tanto a la democratización como a la legitimación científica de la psicología en Chile.

El programa se insertó en el proceso de refundación del Hospital Psiquiátrico El Peral llevado a cabo por el Departamento de Psiquiatría y Salud Mental de la sede sur de la Facultad de Medicina de la Universidad de Chile y el Servicio de Salud Metropolitano Sur. El director del Departamento, el psiquiatra Juan Marconi, convocó al psicólogo Luis Montesinos para diseñar y liderar el Programa de Economía de Fichas. Se formó un equipo de trabajo multidisciplinario, formado por psicólogos, asistentes sociales y terapeutas ocupacionales. Tanto Marconi como Montesinos provenían de experiencias que habían sido interrumpidas abruptamente por el Golpe Militar.

Aun cuando en los programas de salud mental intracomunitaria del área sur de Santiago, hubo aportes de psicólogos, esta participación no estuvo vinculada con el desarrollo de un discurso de la disciplina sobre la salud mental o sobre la psicología comunitaria. Probablemente porque en ese período (1968-1973), paralelamente a la introducción del conductismo, la carrera iniciaba su proceso de legitimación científica y de apertura al mundo social. Interrumpido este proceso por la Dictadura militar, el PEF representó una oportunidad de aplicar una terapia conductista en un programa público, integral y masivo de rehabilitación de pacientes crónicos de una Institución pública, pobre y de estructura asilar. En este sentido, a pesar de las críticas que recibió tempranamente, el conductismo representó en el mundo académico chileno una terapia de cambio y de acción política, que iba de la mano de los cambios culturales y sociales que se imponían desde la sociedad.

Los líderes del proceso, Juan Marconi y Luis Montesinos, coincidieron en que el PEF fue un programa "heroico" que se aplicó bajo las condiciones más adversas en las que una política sanitaria pudiera desarrollarse, sin apoyo oficial, en estado de violación permanente de los Derechos Humanos. Además de eso, la estructura asilar, que se pretendía superar a largo plazo, representó un problema estructural que requería de cambios que estaban fuera del alcance de 
un programa académico. De hecho, hasta el inicio de la reforma psiquiátrica y de salud mental iniciada en Chile a fines del siglo pasado, el abandono por parte del Estado solo profundizó la condición asilar y de miseria del Hospital Psiquiátrico El Peral. Antes y después del PEF hubo otros planes de rehabilitación. Algunos exitosos en el corto o mediano plazo, pero todos, a la larga se transformaron en experiencias desarticuladas, sin proyección. A diferencia de otros programas, el PEF se implementó bajo supuestos teóricos y prácticos que provenían de un proceso de investigación iniciado en la década de 1950, cuando comenzaban a configurarse algunos aspectos cruciales de la identidad de la psiquiatría chilena. Aunque el Golpe Militar interrumpió estos procesos, presentan una continuidad teórico-práctica e identitaria con el Programa de Economía de Fichas.

El programa tuvo resultados positivos concretos, específicamente respecto al alta de pacientes y su vida fuera del asilo. A su alero se crearon instancias de investigación y discusión sobre teorías y técnicas de rehabilitación, grupos de trabajo y publicaciones específicas. En un plano más político, el PEF se desarrolló en un contexto de privación de libertades y de deterioro del papel del Estado en la salubridad pública por lo que, además de una alternativa para mantener políticas públicas y vincularse con el desarrollo histórico de la salud mental en Chile, constituyó una política de resistencia al deterioro progresivo de la situación de las personas asiladas en las instituciones de esta índole. La evaluación desarrollada por el equipo que implementó el PEF identificó como los principales problemas que enfrentaron, la falta de apoyo y seguimiento a los pacientes que eran dados de alta, la carencia de recursos técnicos y económicos y la resistencia institucional y cultural a cambiar la estructura asilar del Hospital Psiquiátrico El Peral.

\section{Referencias citadas}

Aguayo, Enrique, García, Jorge, Ugalde, Francisco. 1977. Uso del condicionamiento operante para modificar la conducta verbal en pacientes psiquiátricos crónicos. Un estudio de casos, Pontificia Universidad Católica de Chile, Tesis para optar al título de psicólogo.

Araya, Claudia, Leyton, César. 2017. “La 'vía chilena' a la psiquiatría social. Propuestas y debates en torno al cambio de modelo de asistencia mental, 1968-1973", en Huertas, Rafael (coord.), Políticas de salud mental y cambio social en América Latina, Madrid, Catarata, pp. 56-82.

Araya, Claudia, Morales S., Nicolás, Leyton R., César. 2020. "Archivo del Hospital Psiquiátrico El Peral: una experiencia de investigación desde la historia cultural de la psiquiatría", en Revista de Historia Social y de las Mentalidades, Vol. 24, no 1, Santiago, pp.147-168.

Araya, Claudia, Martínez, Camila. 2021. "Epidemiología de los trastornos mentales en Chile y su impacto en las políticas públicas de salud mental, 1950-1973", en Asclepio. Revista de Historia de la Medicina y de la Ciencia, Vol. 73, n¹, Madrid, p. 349. Doi: https://doi.org/10.3989/asclepio.2021.15. 
Armijo, M. Alejandra (ed.). 2010. La psiquiatría en Chile. Apuntes para una historia, Santiago, Royal Pharma.

Ayllon, Teodoro, Azrin, Nathan. 1968. The Token Economy. A Motivational System for Therapy and Rehabilitation, New York, Meredith Corporation.

Barraza, Fernando. 1977. "No hay salud mental sin trabajo social: nuevos enfoques en los programas de salud mental subrayan el papel protagónico del trabajador social. Entrevista al doctor Alfredo Pemjean y al psicólogo Rafael Estévez", en Revista de Trabajo Social, 23, Santiago, pp. 36-40.

Basaglia, Franco. 2013. La condena de ser loco y pobre. Alternativas al manicomio, Buenos Aires, Topía.

Caballero, María Soledad, Liberman, Lucía. 1980. Estudio diagnóstico de dos hospitales psiquiátricos chilenos, Pontificia Universidad Católica de Chile, Tesis para optar al título de psicólogo.

Camus, Pablo, Muñoz, Enrique. 2017. Psicología en la UC. Sesenta años de sueños y realizaciones, Santiago, Ediciones Universidad Católica.

Dorna, Alejandro. 1982. "La psicología del comportamiento en Chile entre los años 1970 y 1973", en Revista Latinoamericana de Psicología, Vol. 14, № 2, Santiago, pp. 147-155.

Flores A., Carlos, Mateos M., Laura (coord.). 2019. Recuento histórico del análisis de la conducta, Guadalajara, Universidad de Guadalajara.

García, Jorge, Montecinos, Luis. 1979. “Uso de técnicas de condicionamiento operante en la instauración y mantención de conductas rehabilitadoras en el personal de apoyo", en Revista Chilena de Psicología, 1, Santiago, pp. 19-30.

Gómez, Alejandro. 2010. "La terapia cognitivo-conductual”, en Armijo, M. Alejandra (ed.), La psiquiatría en Chile. Apuntes para una historia, Santiago, Royal Pharma, pp. 216-218.

Gómez, Mauricio. 2005. "La reconversión del Hospital Psiquiátrico El Peral en Red Comunitaria de Salud Mental y Psiquiatría”, en Cuadernos Médico Sociales, 45, Santiago, pp. 285-299.

Gómez, Mauricio, Villanueva, Mario. 2010. “El Hospital Psiquiátrico El Peral”, en Armijo, M. Alejandra (ed.) La psiquiatría en Chile. Apuntes para una historia, Santiago, Royal Pharma, pp.30-47.

Huertas, Rafael (coord.). 2017. Políticas de salud mental y cambio social en América Latina, Madrid, Catarata.

Laborda, Mario, Quezada, Vanetza (eds.). 2010. Notas históricas de la psicología en Chile, Santiago, Universitaria.

Laborda, Mario, Míguez, Gonzalo, Quezada, Vanetza, Lira, Daniela, Arriaza, Tomás. 2019. “Notas para una historia del enfoque conductual en Chile", en Flores A., Carlos, Mateos M., Laura (coord.), Recuento histórico del análisis de la conducta, Guadalajara, Universidad de Guadalajara, pp. 39-81.

León, Ramón. 2014. “Notas acerca de psicólogos y teorías psicológicas de Europa Oriental en la historia de la psicología de América del Sur", en Liberabit, Vol. 20, no 1, Lima, pp. 55-72.

Ligüeño, Sebastián, Parra, Diego, Moncada, Laura, Laborda, Mario. 2010. “La psicología en la Universidad de Chile: Antecedentes históricos y trayectoria de la carrera en el período 1947-1992", en Laborda, Mario, Quezada, Vanetza (eds.), Notas históricas de la psicología en Chile, Santiago, Universitaria, pp. 27-54. 
Luco, Alfonso. 2010. La psicología en Chile. Ciencia, disciplina y profesión, Santiago, Catalonia.

Magaña, Irene, Loubat, Margarita. 2010. "Psicología, salud mental y salud pública: Una mirada panorámica histórico-crítica”, en Laborda, Mario, Quezada, Vanetza (eds.), Notas históricas de la psicología en Chile, Santiago, Universitaria, pp. 193-213.

Marconi T., Juan. 1973. "La revolución cultural chilena en programas de salud mental", en Acta Psiquiátrica y Psicológica de América Latina, 19, Buenos Aires, pp. 17-33.

Marconi, Juan. 1974. "Diseño de un programa integral de salud mental para la ciudad de Córdoba", en Acta Psiquiátrica y Psicológica de América Latina, Vol. 20, n 3, Buenos Aires, pp. 240-246.

Marconi, Juan. 1976. "Política de salud mental en América Latina”, en Acta Psiquiátrica y Psicológica de América Latina, Vol. 22, no 4, Buenos Aires, pp. 112-120.

Marconi, Juan. 1998. Del asilo a la comunidad: 50 años de psiquiatría chilena, 1948-1998. Un testimonio personal, Santiago, documento inédito (Mecanografiado).

Mendive, Susana. 2004. "Entrevista al Dr. Juan Marconi, creador de la psiquiatría intracomunitaria. Reflexiones acerca de su legado para la psicología comunitaria chilena", en Psykhe, Vol. 13, no 2, Santiago, pp. 187-199.

Ministerio de Salud. 1978. "Políticas de Salud Mental", en Archivo de la Administración, Fondo Ministerio de Salud, Santiago.

Minoletti, Alberto. 2006. "Semblanza Juan Marconi Tassara", en Revista Chilena de Neuropsiquiatría, Vol. 44 , no 1, Santiago, pp. 61-62.

Montesinos, Luis. 1976. "Sub-Programa de Rehabilitación Hospital Psiquiátrico Puente Alto. Un programa de Economía de Fichas para el Patio 10", en Archivo Hospital Psiquiátrico El Peral, Serie Documentos Históricos, Santiago, 8 pp.

Montesinos P., Luis, Bravo M., Laura, Tedias N., Miriam, Jara S., Rosa, Peralta A., María Inés, Álvarez G., Ruth, Ríos S., Cristina, Miranda C., Sara, Álvarez P., María Inés, Zanghellini P., Germán. 1978. "Rehabilitación de pacientes mentales crónicos: Una combinación del esquema de delegación de funciones con las técnicas del condicionamiento operante", en Acta Psiquiátrica y Psicológica de América Latina, 24, Buenos Aires, pp. 35-40.

Montesinos, Luis. 1979. "Informe final de la aplicación de un Programa de Economía de Fichas en combinación con el esquema de delegación de funciones, en la rehabilitación de pacientes psiquiátricos crónicos", en Cuadernos de Salud Mental, Psiquiatría y Psicología, Santiago, Departamento de Salud Pública, Salud Mental y Psiquiatría, Facultad de Medicina Sur, Universidad de Chile.

Montesinos, Luis. 2018. "Intervención cultural en pacientes psiquiátricos crónicos del Hospital Sanatorio El Peral: 40 años después”, en Revista de Psicología, Vol. 27, № 1, Santiago, pp. 1-6.

Quezada, Vanetza, Vergés, Álvaro, Laborda, Mario. 2014. “Sergio Yulis: Pasado y Presente del Enfoque Conductual en Chile", en Psykhe, Vol. 23, no 1, Santiago, pp. 1-11.

Roales-Nieto, Jesús, Fernández, Antonio. 1986. “La Economía de Fichas en el tratamiento de pacientes crónicos: el papel del personal institucional”, en Revista Latinoamericana de Psicología, Vol. 18, no 1, Santiago, pp. 23-41. 
Trucco, Marcelo. 1976. "Censo de hospitalizados en establecimientos psiquiátricos", Documento informativo del Minsal, Unidad Técnico Normativa, Departamento de Programa de las personas, en Archivo de la Administración, Fondo Ministerio de Salud, Santiago.

Vera-Villarroel, Pablo Montesinos, Luis Prieto, Arturo. 2010. “Historia del análisis y terapia del comportamiento en Chile", en Laborda, Mario, Quezada, Vanetza (eds.), Notas históricas de la psicología en Chile, Santiago, Universitaria, pp. 283-303.

Yulis, Sergio. 1974. "Terapia del Comportamiento", en Revista Latinoamericana de Psicología, Vol. 6, no 3, Bogotá, pp. 381-402.

Zanguellini, Germán. 1977. “Antecedentes Históricos”, en Archivo Hospital Psiquiátrico El Peral, Santiago, Serie Documentos Históricos.

\section{Otras}

"El Open Door de El Peral será dentro de poco un motivo de orgullo para el país", Diario La Nación, 25 de marzo de 1929, sin autor, p. 1.

González, Mónica. 1985. "Yo torturé. Entrevista a Andrés Valenzuela", Revista Cauce, Separata, Año 2, N.32, pp. 23-29 de julio de 1985.

Luco, Alfonso. 1977. Pabellón 10. Cortometraje Documental. Recuperado de https://www.youtube.com/watch?v=uvqedWhQiBs (Consultado el 9 de agosto de 2020).

Araya I., Claudia y Leyton R., César. 2018. "Entrevista a Armando Becerra”, realizada el 30 de agosto de 2018, Santiago.

Araya I., Claudia y Morales S., Nicolás. 2017. “Entrevista a María Angélica Contreras", realizada el 25 de abril de 2017, Santiago.

Araya I., Claudia. 2019. "Entrevista a Luis Montesinos", realizada por correo electrónico el 16 de julio de 2019. 